\title{
A relevância do local: convergências e divergências entre as abordagens sobre aglomerações
}

\author{
Ana Lúcia Tatsch ${ }^{* *}$
}

\begin{abstract}
Resumo
Este artigo procura, primeiramente, examinar a importância da dimensão espacial/local mesmo diante do processo de globalização alicerçado na difusão das tecnologias de informação e comunicação. E, em segundo lugar, pretende sistematizar várias contribuições presentes na literatura que ressaltam a importância da proximidade territorial no processo de capacitação produtiva e inovativa das empresas. São apresentadas diferentes abordagens que têm como elo comum o entendimento de que as aglomerações, em sentido amplo, facilitam e contribuem para a dinâmica econômica e tecnológica de um espaço territorial específico. Entende-se que o ambiente local não pode ser visto apenas como uma unidade de delimitação geográfica, mas como uma importante unidade de análise, que dá destaque às características socioeconômicas e institucionais de um espaço/território específico, condicionando o desempenho competitivo e inovativo dos agentes ali localizados.
\end{abstract}

Palavras-chave: Dimensão local; Aglomerações; Sistemas produtivos e inovativos locais; Arranjos produtivos locais.

\section{Abstract \\ Local relevance: convergence and divergence between agglomerations approaches}

This paper first seeks to examine the significance of the spatial/local dimension relative to the globalization process, which is based on the diffusion of information and communication technologies. Second, the paper purports to systematize various contributions found in the literature, which highlight the significance of territorial proximity for the process of production and innovation enhancement of firms. Various different approaches are then presented, which share the understanding that spatial clustering, broadly speaking, facilitate and contribute to the economic and technological dynamic of specific territorial spaces. It is understood that the local environment can not be seen merely as a unit of geographical delimitation, but as an important unit of analysis, which emphasizes the institutional and socioeconomic characteristics of a specific area/region, affecting the competitive and innovative performance of the agents located there.

Key-words: Local dimension; Local systems of production and innovation; Local productive arrangement.

JEL O10, R10.

Este artigo procura, primeiramente, examinar a importância da dimensão espacial/local mesmo diante do processo de globalização alicerçado na difusão das

\footnotetext{
* Trabalho recebido em 17 de setembro de 2010 e aprovado em 3 de julho de 2012.

** Professora do Departamento de Economia e Relações Internacionais da Universidade Federal do Rio Grande do Sul (UFRS), Porto Alegre, RS, Brasil. E-mail: analuciatatsch@gmail.com.
} 
tecnologias de informação e comunicação. E, em segundo lugar, pretende sistematizar várias contribuições presentes na literatura que ressaltam a importância da proximidade territorial no processo de capacitação produtiva e inovativa das empresas. São apresentadas diferentes abordagens que têm como elo comum o entendimento de que as aglomerações, em sentido amplo, facilitam e contribuem para a dinâmica econômica e tecnológica de um espaço territorial específico.

O texto está estruturado da seguinte forma: na primeira seção, comentamse as mudanças recentes no cenário mundial, sobretudo aquelas referentes ao crescente processo de globalização da economia, observando-se como a literatura analisa o impacto desse processo nas economias locais. Frente a duas linhas de argumentação - uma que defende a perda de importância da dimensão local, e outra que, em contrapartida, assinala a relevância dos contextos sociais, econômicos e institucionais particulares - procura-se destacar esta última. Já na segunda seção, verifica-se a ênfase atribuída por diversos autores às aglomerações produtivas enquanto lócus de complementaridade entre diferentes agentes, procurando organizar o pensamento das diversas linhas de pesquisa que têm como traço comum o entendimento de que as aglomerações, em sentido amplo, facilitam e contribuem para as dinâmicas econômica e tecnológica de um espaço territorial específico, assim como apresenta-se uma unidade de análise em particular - o arranjo produtivo local. Ao final, ressaltam-se os principais pontos das diversas abordagens tratadas, procurando enfatizar as convergências e as divergências entre elas.

\section{A importância da dimensão local}

Independentemente do entendimento que se possa ter sobre o significado da chamada globalização, parece ser consensual que se vive um estágio recente do antigo processo histórico de internacionalização do capital. Há um conjunto de autores que argumenta que o que de fato se observa é um movimento de globalização das finanças apoiado nas Tecnologias de Informação e Comunicação, no qual se percebem elementos de aprofundamento na internacionalização de capital (também suportado pelas novas tecnologias de base eletrônica), com evidentes assimetrias regionais, setoriais e ocupacionais. Chesnais (1996) e Chesnais e Sauviat (2005) sustentam que o traço mais marcante nesse processo, denominado por eles de "mundialização", é uma total inversão das relações produtiva/financeira, com a produção passando a ser subordinada à lógica financeira.

O conceito de globalização, quando empregado no sentido banalizado de um processo de homogeneização do espaço econômico, é entendido como uma característica inexorável do capitalismo atual. Nessa percepção, a globalização é 
vista como um processo irreversível, cuja tendência implacável de unificação do mercado mundial dissolve fronteiras nacionais e reduz a relevância dos mercados domésticos. Nessa "economia global", crescentemente dominada por empresas transnacionais, os Estados nacionais estariam reduzindo sua presença, tornando-se obsoletos e impotentes (Batista Jr., 1998). Do ponto de vista normativo, isto implicaria limitações à condução de políticas nacionais.

Essa não é a perspectiva aqui adotada. Embora a globalização seja um processo eminentemente geográfico, surpreendentemente, é debatida, no mais das vezes, à margem de sua dimensão espacial (Storper, 1997a). Tem-se, sim, consciência de que o processo de globalização se calca, em contrapartida, em um movimento de concentração da produção, do comércio e dos fluxos de tecnologia nos países desenvolvidos, particularmente naqueles pertencentes à chamada Tríade, e que os Estados nacionais continuam tendo um papel significativo no quadro geopolítico e econômico atual. Logo, o conceito de globalização mormente difundido é absolutamente insuficiente, pois tem-se que incluir uma dimensão espacial para torná-lo analiticamente relevante. Esta é a perspectiva de globalização do presente texto.

Em decorrência de tal falta de entendimento em torno do conceito da globalização e de suas consequências no cenário mundial, não há também consenso na literatura sobre o impacto desse processo nas economias locais ${ }^{1}$.

A visão que entende a globalização como um processo de homogeneização do espaço mundial e de convergência entre os países é também aquela que defende a perda de importância da dimensão local na atual fase do capitalismo. Isto porque, ao destruírem-se as barreiras econômicas, sociais, culturais e políticas, entre os países e regiões, cria-se um mundo desterritorializado, sem fronteiras e sem raízes (Diniz, 2001). O declínio das identidades sob as forças da estandardização levaria então à desconstrução do local enquanto singularidade e à perda de autenticidade das culturas locais diante das influências externas (Albagli, 1999).

A hipótese da convergência entre os países no contexto da discussão sobre a capacidade de preservação dessas identidades é explicada por Boyer (1993) com base em três tendências. Uma primeira ligada à convergência econômica tanto em nível da produtividade quanto em direção a padrões de vida comuns em âmbito mundial. Uma segunda relacionada à tendência à similaridade dos sistemas políticos e econômicos; sistemas análogos combinando democracia e mercados. Isto é, as forças de mercado seriam capazes não só de garantir a eficiência econômica, mas também a ordem democrática. E, por fim, uma terceira tendência vinculada à identidade das formas institucionais e dos modos de regulação.

(1) O texto de Albagli (1999) permite aprofundar esse debate ao discutir o papel do local no contexto de mudanças globais a partir de uma resenha da literatura sobre o tema. 
Para Tavares e Fiori (1997), no entanto, tal convergência está longe de se consolidar. Na realidade, segundo esses autores, tem-se um processo não inclusivo nem homogeneizador decorrente da globalização financeira, e sim assimétrico do ponto de vista do capital, do trabalho e dos espaços regionais ${ }^{2}$.

Em contrapartida à argumentação que apregoa a anulação do espaço, Johnson e Lundvall (2000) assinalam que tal linha de pensamento acaba criando uma falsa dicotomia entre o global e o local. Segundo eles, o que se pode sugerir, isto sim, é que o fenômeno da globalização deve ser combinado ao da localização.

Freeman (1995) sugere que há, de fato, dois processos coexistentes: uma padronização global em algumas áreas e a crescente diversidade em outras. Para ele, apenas determinados produtos ou serviços têm uma demanda naturalmente "global", não importando significativamente as variações locais de gostos, clima etc. Porém, existe certamente um conjunto maior de produtos e serviços para os quais tais aspectos não podem ser ignorados. A partir de tal diferenciação, Freeman também explica a importância que adquire uma série de características locais que, em síntese, conformam os sistemas nacionais e regionais de inovação, exemplificando com uma série de casos históricos, como os da Inglaterra, da Alemanha, das economias socialistas do Leste Europeu, do Japão, da Coréia e do Brasil.

Nessa direção, Humbert (2005, p. 259) argumenta que “a desconexão da produção industrial com o 'capitalismo' ou o 'centro' é uma ilusão, pois a indústria faz parte de um sistema mundial ou global". Entretanto, os processos locais somente captam as oportunidades advindas dos fluxos internacionais de conhecimento e tecnologia se as capacitações domésticas para aproveitá-las forem desenvolvidas previamente. A industrialização depende, então, da dinâmica dos processos de aprendizado localizados, já que são os esforços endógenos, como também as capacidades sociais, que garantem a possibilidade de mudança técnica. Da mesma forma, o processo de inovação e de melhoria da tecnologia de manufatura de produtos envolve um processo de aprendizado eminentemente localizado. Esse autor propõe, portanto, que se utilize a idéia de glocalização, a qual enfatiza o argumento de que se deve valer das dinâmicas globais para alimentar as locais e, somente assim, os desafios da globalização podem se tornar oportunidades.

É nesse sentido que autores como Benko (1996 e 2002) enfatizam a coexistência tanto de um processo de globalização dos fluxos econômicos quanto da reaglomeração visível do território. A ressurgência da produção flexível reforça, de acordo com ele, a dimensão da especialização inter-regional. Assim, apesar da

(2) Autores como, por exemplo, Boyer (1993), Lundvall e Borrás (1997) e Batista Jr. (1998) corroboram esse ponto de vista, aportando inclusive dados estatísticos que reforçam essa argumentação. 
emergência desse sistema global, a economia mundial não deixa de ser um "[...] mosaico de regiões produtivas especializadas, com processos complexos de crescimento localizado, cada vez mais dependente, apesar de tudo, das outras regiões" (Benko, 2002, p. 51). Por conseguinte, a noção de sistema global deve ser vista como um quebra-cabeça de economias regionais e não como uma justaposição de economias nacionais. Portanto, para esse autor, “[...] a territorialidade regional não se analisa como a justaposição dos territórios locais, mas como uma realidade territorial nova que nasce de suas inter-relações" (Ibid, p. 63).

Assim, a partir desse outro conjunto de argumentos, acredita-se que a globalização pode até mesmo influenciar os sistemas locais. Isto porque "[...] não importa onde o sistema social está, ele tem de lidar principalmente com condições e leis físicas que não são de origem local, com características da natureza que não são locais" (Humbert, 2005, p. 261). Porém, esse quadro não anula a importância desses contextos sociais e institucionais particulares. Pelo contrário, a capacidade inovativa e, portanto, competitiva de um país, região ou localidade é resultado, isto sim, das relações entre os atores econômicos, sociais e políticos desses espaços, refletindo suas condições culturais e institucionais próprias (Cassiolato; Lastres, 2005). E ainda mais, dentro dessa ótica, "[...] a globalização e a especialização internacional se baseiam no fortalecimento de distritos e networks regionais" (López; Lugones, 1999, p. 86). Nessa direção, há um conjunto de teses que consideram a dimensão local como fator determinante da capacidade inovativa e que encaram as aglomerações locais como uma alternativa viável e relevante de desenvolvimento econômico. Exatamente esses aspectos serão examinados na próxima seção.

\section{As principais abordagens que privilegiam a dimensão local}

A partir da discussão anterior, percebe-se a importância de incluir a dimensão espacial - em particular aquela sobre os processos locais - num debate sobre capacitação e competitividade no quadro atual da evolução do capitalismo.

Embora existam contribuições antigas que discutem o papel da dimensão territorial na organização das atividades socioeconômicas, como é o caso do trabalho de Perroux (1961), bem como aqueles que analisam o potencial competitivo das aglomerações de pequenas e médias empresas, como o estudo de Marshall (1890), tais aspectos foram deixados de lado pela maioria dos autores da área econômica durante um longo período. Isto, em parte, porque tais questões não estão incluídas no rol de preocupações dos pesquisadores pertencentes ao mainstream da teoria econômica, mas também em razão do papel que a grande empresa adquire a partir do padrão de acumulação mundial estabelecido no pós- 
guerra, quando a estrutura de produção passa a ser calcada na expansão de grandes unidades produtivas e na fabricação em grande escala. No entanto, com a crise do fordismo e a emergência de um novo paradigma baseado na flexibilização ${ }^{3}$, a abordagem espacial ganha novamente destaque ${ }^{4}$. Acresce-se ainda o fato de que os estudos e o debate acerca das aglomerações produtivas ganham também relevância, em função do dinamismo em termos de geração de emprego, de renda e de produtividade que tais configurações asseguram a determinadas regiões nos países desenvolvidos. Exemplos clássicos europeus podem ser mencionados, com destaque para os casos da chamada Terceira Itália, de Baden-Württenberg e da Baviera, na Alemanha, e de Rhone-Alpes, na França.

Logo, esse interesse em torno da temática que busca compreender a dinâmica econômica e tecnológica de uma aglomeração de firmas em um espaço geográfico específico tem produzido vários estudos, gerando uma série de conceituações distintas.

Muitas dessas abordagens tiveram sua origem na discussão do esgotamento do padrão de acumulação mundial estabelecido a partir do pósguerra, que se assentava no complexo metal-mecânico e no setor petroquímico e cuja estrutura de produção era baseada na expansão de grandes unidades produtivas e na fabricação em grande escala. Alguns autores enfatizavam que, com o esgotamento histórico desse modelo, havia a possibilidade e o favorecimento do surgimento de um novo paradigma baseado na integração e na flexibilização (Coriat, 1988).

Nessa direção, Piore e Sabel (1984 e 1989) analisam a deterioração do desempenho econômico dos países avançados como resultado dos limites do modelo de desenvolvimento industrial calcado na produção em série, sugerindo o nascimento de um novo modelo de organização industrial, o qual é denominado por eles "especialização flexível" "É com base nesse conceito que ganha corpo a discussão a respeito dos distritos industriais, uma vez que tais distritos são a forma

(3) Para uma discussão sobre a crise do paradigma fordista, ver, por exemplo, Ominami (1986), Perez (1986), Piore e Sabel (1989), Leborgne e Lipietz (1992) e Coutinho (1992).

(4) As noções de território e de espaço estão sendo empregadas aqui sem uma preocupação rígida de distinção, embora, a literatura possa conceituar território distintamente de espaço ou de lugar, pois o primeiro estaria associado à idéia de domínio ou de gestão de uma determinada área, logo, vinculado à noção de poder Nesse sentido, ver, por exemplo, Andrade (2002) e Greiger (2002).

(5) Para uma discussão do conceito e das críticas feitas a ele, veja o próprio trabalho de Piore e Sabel (1984 e 1989), bem como Schmitz (1989) e Storper (1997a). Vale ressaltar o entendimento que se tem de que as novas condições da concorrência internacional, as quais impõem o aumento da flexibilidade produtiva e favorecem a organização na forma de distritos de pequenas empresas, não excluem a importância das grandes empresas nesse novo contexto. Do mesmo modo, acredita-se que também os mercados para bens manufaturados em série não necessariamente se esgotam, mesmo que sejam requeridos produtos diferenciados. 
espacial dessa especialização flexível $^{6}$ (Benko, 1996). Esse termo de distritos industriais já havia sido empregado por Marshall (1890), quando de sua análise das pequenas empresas inglesas especializadas em determinados produtos manufaturados que se aglomeravam em centros produtores no século XIX, mas é agora retomado e rediscutido a partir das experiências exitosas, principalmente a da chamada Terceira Itália.

Surge, daí, um conjunto de trabalhos que analisam as peculiaridades das aglomerações italianas através da noção marshalliana de distrito industrial. Os estudos de Becatini (1990) e Brusco (1990 e 1992) podem ser citados como importantes referências dessa linha de abordagem. O conceito empregado define o distrito industrial como um conjunto de empresas localizadas em uma área geográfica relativamente pequena que atuam em um mesmo mercado e que compartilham valores e conhecimentos que conformam um ambiente cultural próprio. Essas firmas ligam-se umas às outras através de relações específicas dentro de um mix de competição e cooperação (Brusco, 1992, p. 178-79). Esse ambiente cultural próprio é definido a partir da noção de que os distritos industriais possuem uma "atmosfera industrial" que compreende convenções e valores comuns e, portanto, um conjunto de aspectos intangíveis que estão presentes nessas configurações.

Ao examinarem a dinâmica que se estabelece internamente às aglomerações, tais trabalhos procuram evidenciar que a necessidade de aumento da flexibilidade produtiva (a qual implica incremento da qualidade de produtos, de velocidade e de flexibilidade de resposta a uma demanda segmentada, requisito das novas condições de concorrência internacional) pode ser potencializada nesse tipo de organização industrial. A descentralização vertical torna também fundamentais as relações interfirmas no que diz respeito à geração e à incorporação de inovações. Ou seja, as aglomerações aparecem como lócus de complementaridade entre as firmas, permitindo o estabelecimento de redes de empresas. Tal complementaridade não exclui a concorrência entre os atores, mas sim, torna evidente o binômio competição-cooperação.

Outro conjunto de autores, dentre os quais se pode destacar, primeiramente, Schmitz (1989), mas também outros pesquisadores, como

(6) A especialização flexível pode manifestar-se sob outras formas, além dos distritos industriais, como, por exemplo, sob a forma de redes de empresas ou de sistemas de subcontratação comandados por grandes empresas (Garcia, 1996). Do mesmo modo, a indústria em pequena escala não necessariamente significa especialização flexível, já que esta última implica estreitas relações interfirmas (Schmitz, 1989). Assim, deve ficar claro que o conceito de especialização flexível não tem como objetivo definir e discutir as características dos distritos industriais. 
Rabelloti (1995), Nadvi (1994, 1996), Van Dijk e Rabellotti (1997)7, acreditam que a concentração regional e setorial de pequenas e médias empresas proporciona maior facilidade para a ação conjunta, permitindo ganhos para a aglomeração como um todo. De forma geral, esses autores entendem que as aglomerações se caracterizam pela concentração geográfica de determinado setor ou cadeia de produção, onde a desverticalização do processo produtivo permite o estabelecimento de redes de cooperação e, portanto, uma especialização com complementaridade entre as empresas, o que não se estabelece apenas entre firmas, mas também entre estas e instituições de pesquisa e de capacitação e de coordenação local. Ou ainda, em outras palavras, para esses autores, tais aglomerações possibilitam ganhos competitivos às empresas, à medida que se caracterizam por compreender: um conjunto de pequenas e médias empresas, concentradas espacialmente e especializadas setorialmente; uma série de articulações para frente e para trás, ambas baseadas nas trocas comerciais e não comerciais de produtos (informações e pessoas); uma bagagem social e cultural comum, ligando os agentes econômicos e criando um código de conduta e de comportamento, algumas vezes explícito, mas frequentemente implícito; além de uma rede de instituições locais, públicas e privadas, dando suporte aos agentes econômicos que lá atuam (Rabelloti, 1995).

Um conceito relevante para esta análise é o conceito elaborado por Schmitz de "eficiência coletiva", o qual pode ser entendido a partir da afirmação desse autor de que a capacidade de adaptar-se à mudança é que determina o desempenho econômico, mas tal capacidade não pode ser entendida focalizando-se apenas em uma determinada empresa; o que existe, isto sim, é uma capacidade coletiva de lidar com as mudanças no mercado. A eficiência coletiva é, então, entendida como a vantagem competitiva que se estabelece nas aglomerações, derivada de externalidades locais e da ação conjunta das empresas. É ela que determina o desempenho econômico da aglomeração (Schmitz, 1989; Humphrey; Schmitz, 1996). No entanto, mesmo onde surja uma capacidade coletiva para competir, adaptar e inovar, não se deve esperar uma ilha de unidade e solidariedade. A eficiência coletiva é resultado de processos internos, nos quais determinadas empresas prosperam e outras declinam. Logo, a noção de eficiência coletiva não exclui o conflito ou a competição entre as empresas da aglomeração; pelo contrário, tal processo de aglomeração torna o mercado mais transparente e induz à rivalidade local, como também favorece as ações conjuntas para resolução de problemas (Schmitz, 1995, p. 534).

(7) Schmitz é pesquisador do Institute of Development Studies (IDS), da Universidade de Sussex. Ele e os demais pesquisadores citados organizaram um número especial da revista World Development (Schmitz; Nadvi, 1999), no qual apresentam seus trabalhos e desenham uma agenda de pesquisa. 
Vale mencionar a distinção feita por esses pesquisadores entre cluster, distrito industrial e network. O cluster é definido enquanto uma concentração setorial e geográfica de empresas. A especialização e a cooperação que ali se desenvolvem são objeto das pesquisas empíricas, mas não fazem parte de sua própria definição. Os distritos industriais, por sua vez, emergem quando um cluster desenvolve mais que a especialização e a divisão do trabalho entre firmas; quando desenvolve formas explícitas e implícitas de cooperação entre os agentes locais desses distritos, permitindo, assim, uma melhora na produção local e nas capacidades inovativas, e, ainda, desenvolve fortes associações setoriais. Desse modo, os clusters podem ter mais ou menos as características de um distrito, e as políticas devem procurar promover e desenvolver a sua eficiência coletiva. Por conseguinte, os clusters podem existir sem a evidência de aspectos relativos à eficiência coletiva, os quais são associados ao modelo de distrito industrial; da mesma forma, a cooperação entre firmas pode ocorrer sem a existência de um cluster. E as redes de pequenas e médias firmas (network) podem existir sem que essas empresas estejam na mesma localidade. Nesse caso, as externalidades econômicas tendem a ser pequenas, mas não deixam de proporcionar ganhos coletivos aos envolvidos (Humphrey; Schmitz, 1996, p. 1863).

Em síntese, esse grupo de pesquisadores, que tem na figura de Schmitz sua maior referência, segue a linha de abordagem dos autores italianos, embora utilize geralmente o termo cluster, no sentido antes referido, ao invés de distrito industrial, e se valha da definição de eficiência coletiva como conceito fundamental para frisar os ganhos de eficiência da ação conjunta das organizações.

Além desse grupo de autores que calcam seus trabalhos no conceito de distrito industrial a partir da noção marshalliana, há ainda outras possíveis abordagens que também privilegiam a idéia de aglomerações locais. Esse é o caso da noção de sistemas industriais localizados ou sistemas produtivos locais introduzida por pesquisadores franceses a partir da análise da realidade européia, cujo principal representante é Courlet $(1993,2001)$.

O sistema industrial localizado é definido como:

[...] uma configuração de empresas concentradas em um espaço de proximidade em torno de um ou de vários setores industriais. As empresas interagem entre si e com o meio sócio-cultural de inserção. Essas relações não são apenas mercantis, mas também informais, e geram externalidades produtivas para o conjunto das empresas (Ibid,, p. 10).

Tais sistemas calcam-se em relações de colaboração, de médio e longo prazos, entre empresas que realizam produções conjuntas conforme pactos específicos. Assim, há uma densa rede de interdependências entre os agentes. Esses sistemas organizam-se, geralmente, a partir de empresas relativamente iguais e/ou autônomas entre si, de modo que sua base seja explicitamente territorial. A história 
própria de cada país e região, bem como as práticas e estratégias industriais seguidas em nível nacional devem também ser levadas em conta.

Contudo, tais sistemas não são necessariamente formados por pequenas e médias empresas, já que existem relações muito territorializadas entre grandes empresas e entre grandes grupos e pequenas e médias empresas. Logo, quando a rede de colaboração se der primeiramente entre pequenas e médias empresas, estáse falando, segundo o próprio autor, dos chamados, e já comentados, distritos industriais. Nessa situação, a territorialidade do distrito é dada por "[...] um espaço localizado de relações funcionais que se instauram entre o conjunto de empresas e a comunidade de habitantes e que delimitam um sistema territorial de trocas entre si" (Ibid, p. 11). Porém, posteriormente, essa rede de colaboração pode conformarse entre somente grandes empresas e entre grandes grupos e pequenas e médias empresas. Assim, segundo o próprio Courlet (2001), a noção de sistemas produtivos locais é mais ampla do que a de distrito industrial. Tal noção pode, assim, de acordo com o mesmo autor, ser definida como um conjunto caracterizado pela proximidade de unidades produtivas, no sentido amplo do termo - empresas industriais, de serviços, centros de pesquisa e de formação, dentre outros -, que estabelecem entre si relações de intensidade mais ou menos fortes, as quais podem ser formais, informais, materiais, imateriais, mercantis, ou não mercantis, e baseiam-se em fluxos de materiais, de serviços, de mão-de-obra, de tecnologias e, ainda, de conhecimentos.

De todo modo, esses sistemas usufruem economias de aglomeração, que são resultado das intensas relações entre as firmas locais. Essas firmas valem-se da divisão do trabalho, o que permite uma progressiva especialização produtiva e a introdução de novas tecnologias e de uma maior eficácia do sistema local. São essas economias de aglomeração que conferem aos sistemas, de certa forma, economias de escala típicas das grandes fábricas integradas. E quanto mais desenvolvido for o sistema, maiores serão tais economias de aglomeração. Neste ponto, é interessante sublinhar que essas idéias vão ao encontro e se assemelham à noção de "eficiência coletiva" elaborada por Schmitz e discutida anteriormente.

Courlet (2001) acrescenta que a noção de sistemas produtivos locais não se deriva apenas da idéia de distrito industrial, mas inspira-se, igualmente, nas análises da economia industrial e da economia regional sobre a inovação. Por consequência, paralelamente às externalidades que afetam a função de produção nos distritos industriais, existem externalidades que nascem a partir do tecido de conhecimentos. Assim, as firmas localizadas próximas geograficamente têm mais oportunidade de trocar informalmente ou formalmente tais conhecimentos. Há, portanto, "um tecido espacial de conhecimentos". Logo, os efeitos da proximidade espacial ganham contornos importantes também nos processos inovativos, e a inovação adquire uma conotação mais territorializada 
Na sequência, vale ressaltar outras duas contribuições que têm seu foco em dois aspectos agora mencionados: o território e a inovação. O primeiro aspecto ganha destaque nos estudos da chamada "Escola Californiana"; e o segundo adquire importância sine qua non nas pesquisas de viés neo-schumpeteriano e evolucionista.

Dentre os autores do grupo de geógrafos californianos, pode-se citar particularmente Storper (1997a, 1997b), Scott (1998) e Markusen (1995, 1999). Segundo o próprio Storper (1997a), a "Escola Californiana", diferentemente da abordagem da especialização flexível (relacionada, por ele, aos autores italianos que se valem do conceito marshalliano de distrito industrial), aborda a questão dos novos paradigmas de produção e o problema da região a partir da perspectiva de diferentes indústrias (como, por exemplo, as indústrias da televisão e do cinema de Hollywood) - através de qualquer mix de firmas, de diferentes tamanhos e de setores diversos - e de um conjunto político-institucional também diverso, seguindo, assim, uma rota teórica alternativa.

Nesse caso, a discussão a respeito da flexibilidade da produção vincula-se à questão das aglomerações via uma análise dos custos de transação associados às relações interfirmas. Assume-se que certas condições de mercado, exógenas ou endógenas, implicam maior incerteza ("desintegração"), que, por sua vez, pode maximizar os benefícios da especialização e minimizar o perigo de um lock-in tecnológico. Essa desintegração da produção torna também os custos de transação mais altos, pois as transações externas à firma passam a ser mais frequentes e complexas, aumentando seus custos, em decorrência da distância geográfica e da sua complexificação (especialmente quando conhecimentos tácitos e não codificados são requeridos). Por consequência, as aglomerações passam a ser vistas como forma de minimização desses custos de transação. Isto porque, quando da ocorrência dessas aglomerações, as vantagens da interdependência - flexibilidade, minimização de riscos, especialização - são aumentadas, e, no extremo oposto, quando a proximidade geográfica não ocorre, essas vantagens são canceladas, devido ao incremento dos custos ou à dificuldade de intensificar as transações. As vantagens das aglomerações calcam-se, então, nas economias externas, em razão da minimização desses custos de transação. Porém, ainda conforme o próprio Storper, outros aspectos, além daqueles relativos aos custos de transação, devem ser incorporados nessa discussão. Nesse sentido, ao concluírem que as aglomerações são elas próprias fontes da dinâmica industrial (uma vez que se constituem em comunidades industriais onde ocorre o desenvolvimento de uma dinâmica tecnológica e do conhecimento endógeno), explicitam que a localização e as regras de comunicação ali adotadas são importantes para a inovação em algumas indústrias. Essa compreensão levou o grupo a refletir sobre as questões institucionais, porque, quando as potenciais economias externas de uma 
aglomeração se realizam, nada garante que os mercados sozinhos, nem as várias formas de contratos, coordenem com sucesso as transações que lá ocorrem, pois tais transações - seja no mercado de trabalho, nas relações interfirmas, seja no desenvolvimento inovativo - tendem a ter pontos de falha, quando da ausência de instituições adequadas (Storper, 1997a, p. 9-14).

Ainda dentro dessa abordagem, com base em estudos empíricos nos Estado Unidos, no Japão, na Coréia do Sul e no Brasil, Markusen $(1995,1999)$ analisa experiências de áreas de atração de investimentos que vão além daquelas cujas características são atribuídas ao modelo tradicional de distritos industriais que explicam o caso clássico da Terceira Itália ${ }^{8}$. Nessas outras experiências, a ênfase não está nas pequenas empresas, mas sim nas grandes corporações multinacionais e no poder dos governos. Diante dessas evidências, apresenta uma tipologia que distingue quatro tipos de espaços industriais: os distritos industriais marshallianos, caracterizados, basicamente, por uma estrutura dominada por pequenas empresas, cujas transações intradistritais são intensas e de alta relevância para sua dinâmica; os distritos centro-radiais ( $h u b$ and spoke), onde existem, normalmente, uma ou mais grandes empresas âncoras que ditam o dinamismo do distrito em função de sua posição nos mercados nacional e internacional e estabelecem fortes relações com fornecedores locais; os distritos plataformas-satélite, que se apóiam nas empresas multiplantas e são dominados por grandes firmas externas ao distrito, cujas transações intradistritais são mínimas; e os distritos industriais ancorados em uma instituição governamental, como, por exemplo, uma instalação militar, uma instituição de pesquisa ou alguma empresa estatal. A autora ressalta que, na realidade, um distrito pode apresentar características de mais de um tipo, bem como pode mudar com o passar do tempo. Sua contribuição está, especialmente, em identificar e caracterizar um conjunto de experiências de aglomerações de empresas diferente em suas características-chave e em seus resultados em termos de distribuição de renda e bem-estar, já que, como enfatiza, o modelo dos distritos industriais italianos é insuficiente para explicar a realidade diversa onde as aglomerações exercem um relevante papel.

No que tange às pesquisas de tradição neo-schumpeteriana e evolucionista $^{9}$, estas têm destacado justamente o papel crucial das inovações na

(8) Markusen, além da contribuição ora apresentada, em trabalhos mais antigos, influenciou a retomada da discussão do regionalismo nos anos oitenta. A partir da abordagem marxista, discute os conceitos de região e regionalismo (Markusen, 1981). Uma análise do trabalho dessa autora nesse período é feita por Pacheco (1998).

(9) Não há a pretensão de se realizar aqui uma análise exaustiva das contribuições da abordagem teórica neo-schumpeteriana e evolucionista. Para uma discussão aprofundada, outros trabalhos podem ser consultados. Freeman (1996), por exemplo, faz uma interessante síntese das principais conclusões das pesquisas desenvolvidas pelos autores neo-schumpeterianos. Ver também Nelson e Winter (1982), Dosi (1988) e Possas (1989). 
busca pela diferenciação e obtenção do lucro ${ }^{10}$, bem como frisado o quão sistêmicos são esses processos inovativos e de mudança técnica. Isto é, as firmas não inovam isoladamente, mas através da interação com outras organizações, que podem ser, por exemplo, outras firmas, universidades ou institutos de pesquisa. Do mesmo modo, o comportamento das firmas é também influenciado pelo contexto institucional, isto é, pelas leis, normas e regras sociais, que podem incentivar ou restringir tais inovações (Edquist, 1997). Por conseguinte, o desempenho inovativo de uma economia não é determinado apenas pelas características e habilidades das firmas individuais e de outras organizações, mas muito mais pelos diferentes tipos de relações entre elas e as formas de interação com cada uma delas e com o setor governamental (Johnson, 1997, p. 37).

Dentro desse contexto, Maskell e Malmberg (1999, p.173), por exemplo, sugerem que as empresas constroem sua competitividade de forma interativa com as capacitações que são fundamentalmente localizadas, pois se baseiam na infraestrutura e em ambientes locais, nos recursos naturais, no arcabouço institucional, nos conhecimentos e nas habilidades também locais. Tais "capacidades localizadas" são moldadas e influenciadas pelos processos históricos vivenciados nas diferentes localidades. Portanto, a região, o território ou mesmo o espaço não devem ser vistos como um container de fatores atrativos que podem, ou não, existir, mas sim, como um meio onde ocorre o aprendizado coletivo, a partir de intensas interações entre os diversos atores ali presentes (Maskell; Malmberg, 1999, p. 174).

Assim, um dos elementos-chave desses estudos compreende a percepção de que os processos de inovação são gerados e sustentados por meio de relações interfirmas e, sobretudo, através de relações que se estabelecem entre os atores integrantes de circuitos inovativos em nível intra-regional. Da mesma forma, esse conjunto de autores, ao perceber que o aprendizado interativo é um fator crucial no novo contexto de desenvolvimento econômico e tecnológico, ressalta a proximidade geográfica como o melhor ambiente para promover o intercâmbio de conhecimentos tácitos, destacando a importância crescente das aglomerações industriais locais e regionais enquanto fator fundamental na busca de competitividade e de dinamismo tecnológico de firmas de diferentes setores (Lastres; Vargas; Lemos, 2000).

Dentre esses trabalhos que se calcam no pensamento neo-schumpeteriano e evolucionista, pode-se citar aqueles que propõem e se valem do conceito de

(10) O estímulo à introdução de inovações dá-se pela busca de oportunidades lucrativas e pelo maior poder de mercado. O objetivo de inovar ou imitar rege, assim, as estratégias adotadas pelas firmas. Dessa forma, o caráter dinâmico da economia industrial passa a ser dado pelo processo de inovação, marcado por três dimensões principais, quais sejam: a cumulatividade do progresso técnico, a oportunidade tecnológica e a apropriabilidade privada dos efeitos da mudança técnica (Dosi, 1984, p. 88). 
sistemas nacionais de inovação. Este conceito nasceu nos anos 80 do século passado, especialmente a partir dos trabalhos de Freeman, Lundvall e Dick Nelson, e difundiu-se rapidamente em anos recentes. Tal disseminação deu-se, talvez, em função da limitação das políticas e das teorias vinculadas ao mainstream em compreender e controlar os fatores por detrás da competitividade internacional e do desenvolvimento econômico, ou, ainda, em razão da necessidade de se ter um conceito analítico que auxilie a implementação de políticas. Já ao longo dos anos 60 e 70, organizações internacionais, como a OCDE, preocupavam-se em compreender por que as economias apresentavam taxas de crescimento diversas, e uma das respostas estava vinculada às diferenças entre os sistemas de pesquisa dos diversos países. No entanto, parecia óbvio que os novos conhecimentos requeridos pelas inovações não advinham exclusivamente das universidades, mas de outras tantas fontes. A questão era integrar essas diversas contribuições em um único conceito relativo ao processo inovativo (Lundvall et al., 2002) ${ }^{11}$.

Conforme Johnson e Lundvall (2000, p. 113), o conceito de sistema nacional de inovação pode ser entendido como uma síntese de dois outros national systems of production e national business systems -, pois coloca como centro da análise a co-evolução das estruturas econômicas e institucionais e procura entender como essa co-evolução afeta a produção e o uso do "capital intelectual". Os processos de produção e de inovação caracterizam-se por diferentes aspectos. Enquanto o processo de produção tende a desenvolver rotinas, o processo de inovação é contínuo, cumulativo e calcado na criatividade. No entanto, tais processos, embora distintos, são também interdependentes. Isto porque o aprendizado pode se dar na produção através, por exemplo, do learning-by-doing, gerando subsídios para o processo inovativo; já o processo de inovação é responsável por reestruturar o sistema de produção. Logo, tal interdependência entre produção e inovação legitima a idéia de considerar o sistema nacional de produção como ponto de partida para a definição do sistema de inovação (Lundvall, 1988).

Esse conceito de sistema nacional de inovação é sistêmico, na medida em que salienta que a performance da inovação depende não só das capacidades inovativas das firmas individuais, mas também de como essas interagem entre si e

(11) Nesse interessante artigo, Lundvall et al. (2002) comentam o surgimento e a difusão do conceito de "sistema nacional de inovação", bem como discutem os desafios tanto de um aprofundamento teórico do conceito quanto a adaptação deste para análises em países em desenvolvimento. Freeman (1995), por sua vez, ressalta a influência de Friedrich List na concepção do termo, uma vez que, segundo ele, esse autor analisa muitas das características do sistema nacional de inovação que estão presentes nos estudos contemporâneos, como as instituições educacionais e de treinamento, os institutos de ciência e tecnologia, o aprendizado interativo produtorusuário, e ainda enfatiza o importante papel do governo na coordenação e na implementação de políticas de longo prazo para a indústria e para a economia; embora, é claro, não tenha antecipado outros tantos aspectos que estavam por vir e que também fazem parte do conceito. 
com o setor financeiro, com instituições de pesquisa e com o governo (Johnson; Lundvall, 2000, p. 113). Os sistemas de inovação são, então, entendidos como um conjunto de diferentes instituições que influenciam a capacidade inovativa e de aprendizado de países, regiões e localidades. Logo, os processos de inovação que ocorrem em nível da firma são resultados das relações estabelecidas por ela com outras empresas e organizações, e, por consequência, a inovação é compreendida como um fenômeno sistêmico e interativo, caracterizado por distintas formas de cooperação (Cassiolato; Lastres, 2005). Em síntese, o conceito salienta que é essa complexa composição institucional que impulsiona o progresso tecnológico e promove o desenvolvimento dos países e das regiões (Albuquerque, 2004).

A partir dessa visão, conclui-se que não é fácil, nem possível, replicar a estrutura dos sistemas nacionais de produção e inovação, já que os desempenhos nacionais quanto à inovação estão atrelados ao desenho social e institucional específico deles, bem como às suas características culturais e históricas particulares (Lundvall, 1988).

Vale ainda deter-se na chamada versão de Aalborg ${ }^{12}$ sobre o conceito de sistema nacional de inovação, a qual pode ser vista como a combinação de quatro elementos: a reinterpretação neo-schumpeteriana dos sistemas nacionais de produção; o trabalho empírico baseado na teoria do mercado doméstico do comércio internacional; a visão micro de inovação como um processo interativo (baseado nas pesquisas do $\mathrm{SPRU}^{13}$ ); bem como, a avaliação do papel das instituições no desenvolvimento das atividades inovativas. Essa versão foi desenvolvida para embasar uma melhor compreensão do crescimento econômico e da especialização comercial nas pequenas economias abertas, caracterizadas por uma alta renda per capita e por uma fraca presença de empresas science-based, como é o caso dinamarquês. Logo, os próprios autores do conceito de sistema nacional de inovação reforçam a necessidade de adaptar tal approach à situação dos países em desenvolvimento, nos quais, normalmente, esse sistema se encontra em construção (Lundvall et al., 2002).

Com base nessa concepção, emerge outra proposta conceitual, a de sistema local de inovação ou, ainda, de sistemas e arranjos produtivos locais, que busca exatamente melhor refletir as características dos países em desenvolvimento, como

(12) A Universidade de Aalborg, na Dinamarca, acolhe o grupo de pesquisa IKE - Inovation, Knowledge and Economic Dynamics - que tem contribuído para a construção teórica do conceito de sistema nacional de inovação, especialmente, através de dois de seus pesquisadores: Bengt-Åke Lundvall e Björn Johnson. Para uma discussão aprofundada da versão de Aalborg e da evolução do conceito, ver Lundvall et al. (2002). Vale ainda consultar Albuquerque (2004) que analisa a história de elaboração desse conceito e as contribuições de seus formuladores.

(13) SPRU - Science and Technology Policy Research - University of Sussex. 
o Brasil. Segundo as pesquisas desenvolvidas pela Rede de Pesquisa em Arranjos e Sistemas Produtivos e Inovativos Locais (RedeSist) ${ }^{14}$, partir da noção de sistema de inovação possui algumas vantagens do ponto de vista dos países menos desenvolvidos. Isto porque essa noção sublinha a importância da inovação como fonte de dinâmica competitiva, ao invés de enfatizar as tradicionais vantagens comparativas conhecidas como "espúrias", relativas ao baixo custo da mão-de-obra e à exploração dos recursos naturais sem uma perspectiva de longo prazo. Da mesma forma, o entendimento da inovação como um processo determinado socialmente e fruto de um contexto específico contribui para desmistificar as idéias sobre a aquisição externa e a geração de tecnologias em países subdesenvolvidos. A perspectiva aberta por essa abordagem de sistemas de inovação de ligar as dimensões micro, meso e macro da competitividade é também crucial para o entendimento da realidade dos países e, em especial, daqueles menos desenvolvidos (Lastres; Cassiolato, 2005, p. 3).

Esses pesquisadores definem os sistemas produtivos e inovativos locais como "[...] conjuntos de agentes econômicos, políticos e sociais, localizados em um mesmo território, desenvolvendo atividades econômicas correlatas e que apresentam vínculos expressivos de produção, interação, cooperação e aprendizagem". Portanto,

[...] geralmente incluem empresas - produtoras de bens e serviços finais, fornecedoras de equipamentos e outros insumos, prestadoras de serviços, comercializadoras, clientes, etc., cooperativas, associações e representações e demais organizações voltadas à formação e treinamento de recursos humanos, informação, pesquisa, desenvolvimento e engenharia, promoção e financiamento (Redesist, 2005, p. 1).

Já os arranjos produtivos locais não são considerados sistemas, em razão da articulação entre os agentes ser ainda ausente ou incipiente.

Esses conceitos se colocam como complementares àqueles presentes na literatura econômica (como: setores, complexos industriais e cadeias industriais), pois, para se compreender a dinâmica de um arranjo e conhecer em profundidade suas especificidades, é necessário também se entender seu peso e seu papel nas cadeias industriais e nos setores em que se insere. Todavia, do ponto de vista metodológico, a análise a partir da noção de arranjos produtivos locais auxilia na superação de insuficiências dessas abordagens tradicionais. A classificação tradicional de setor, por exemplo, não permite captar situações em que as fronteiras dos setores não são tão bem demarcadas, em razão da crescente complexidade e do

(14) A RedeSist tem sua coordenação geral sediada no Instituto de Economia da UFRJ, sob a responsabilidade dos Professores José Eduardo Cassiolato e Helena Lastres. Consultar: $<$ http://www.redesist.ie.ufrj.br>. 
entrelaçamento das atividades produtivas. Da mesma forma, a base de competitividade das empresas não se restringe a um único setor, porque é fortemente associada a atividades e capacitações para frente e para trás ao longo da cadeia de produção. Soma-se, ainda, uma certa dificuldade de caracterizar muitas empresas em termos setoriais, uma vez que os novos formatos organizacionais privilegiam a descentralização e a terceirização, dificultando a conformação dos limites das próprias empresas (Cassiolato; Lastres, 2003).

Logo, levando-se em conta tais dificuldades, o conceito de arranjo produtivo local pretende ser uma unidade de investigação que vai além da tradicional visão baseada na organização individual (empresa), no setor ou na cadeia produtiva, visto que estabelece uma ligação entre o território e as atividades econômicas, que também não se restringem aos cortes clássicos espaciais de municípios ou microrregiões (Ibid).

Além disso, a unidade "arranjo" tem também a vantagem de privilegiar o foco em grupos de agentes - empresas, organizações de P\&D, ou voltadas para a educação e o treinamento, ou ainda atinentes à promoção e ao financiamento. Nesse sentido, possibilita que se analise o espaço onde se criam as capacidades produtivas e inovadoras, e, portanto, onde se dá o aprendizado e se intercambiam conhecimentos tácitos. Além disso, representa o nível no qual as ações de política podem ser mais efetivas.

Assim, uma vez que se tem clara a importância da dimensão espacial e do local para entender a produção, mesmo diante do fenômeno da globalização, bem como se reconhece a relevância das interações entre os diversos atores (firmas e outras tantas organizações) para se compreender os processos de geração de conhecimento e de criação e difusão de inovações, percebe-se que a unidade "arranjo", ao incorporar esses aspectos em seu foco de investigação, supera as unidades de análise tradicionais e permite melhor apreender a realidade atual. Tal unidade permite ainda um importante desdobramento em termos de políticas, já que os elementos-chave do conceito sinalizam os focos de ação. Logo, dimensões como enraizamento, adensamento e aprendizado devem orientar a construção das políticas voltada para o local. E seus instrumentos devem estar voltados para o estímulo à promoção das mais diversas formas de aprendizado e, portanto, para a criação e difusão de conhecimentos, e assim, consequentemente, para os processos inovativos, desenvolvendo capacitações produtivas e inovadoras e reforçando e ampliando a competitividade de um dado território. 
Finalmente, para fechar esta seção, é importante recuperar os principais pontos das diversas abordagens tratadas ${ }^{15}$, procurando ressaltar as convergências e as divergências entre elas. Parece nítido que o aspecto central que une as diferentes proposições comentadas é o entendimento de que a dinâmica e a competitividade de um espaço particular vinculam-se às suas peculiaridades locais. Ou melhor, são as características locais, quanto aos aspectos econômicos, sociais e políticos, que conformam as possibilidades de desenvolvimento e crescimento de um entorno espacial específico. Nesse sentido, há um consenso de que a análise das aglomerações deve contemplar um exame das relações interfirmas, mas também destas com outras tantas organizações de caráter privado, ou não, voltadas para atividades produtivas, ou não. Da mesma forma, há concordância a respeito da importância que adquire o arcabouço institucional dessas configurações particulares. Enfim, parece também existir um acordo entre as diversas proposições de que a proximidade territorial é um elemento importante, mas não suficiente, para garantir dinamismo tecnológico aos agentes ali presentes. A partir desse pano de fundo comum, as diversas linhas de trabalho podem ser comparadas.

Os autores italianos, do mesmo modo que os pesquisadores do IDS, focam sua análise na compreensão das relações virtuosas que se estabelecem internamente aos aglomerados, que, por sua vez, são basicamente definidos como um conjunto de pequenas e médias empresas concentradas geograficamente e especializadas setorialmente. A noção de eficiência coletiva auxilia o destaque na preocupação em enfatizar-se que é a ação conjunta dessas firmas com outras tantas organizações que permite ganhos ao aglomerado. No entanto, esses dois enfoques, que não são idênticos, mas que se complementam, privilegiam em demasia as relações entre empresas de um porte específico - pequenas e médias - e, particularmente, de setores tradicionais. Da mesma forma, ficam bastante circunscritos a uma análise interna às aglomerações. $\mathrm{O}$ próprio Schmitz, em trabalhos mais recentes, enfatiza a necessidade de incorporar à discussão as relações que se estabelecem com agentes

(15) Cabe mencionar que, além das várias abordagens comentadas, outras duas poderiam ser ainda citadas. Para conhecimento do leitor, apenas serão elencadas. A primeira refere-se à chamada "nova geografia econômica", que tem em Krugman (1995) sua maior referência. Nessa proposição, os retornos crescentes de escala são associados à aglomeração espacial das firmas. A segunda é aquela capitaneada por Porter (1998) e insere-se na literatura de negócios. Nessa visão, a competitividade no atual contexto de uma economia globalizada é resultado de fatores locais que determinam a dinâmica das firmas líderes. Para uma discussão aprofundada, ver os próprios autores - Krugman (1995) e Porter (1998) -, mas também outros que comentam essas abordagens: Storper (1997a), Humphrey e Schmitz (2000), Suzigan et al. (2000), Vargas (2002), Lastres e Cassiolato (2005), e Garcia (2006). 
externos à aglomeração ${ }^{16}$. Nesse sentido, Schmitz propõe que se compreenda a inserção dos atores locais em cadeias globais de produção ${ }^{17}$.

Outras linhas de pensamento emergem procurando agregar novos elementos. Dentre elas, pode-se citar tanto a abordagem francesa dos sistemas produtivos locais, quanto aquela proposta pelos geógrafos californianos. Ambas se opõem às abordagens que se calcam no conceito marshalliano de distrito industrial, à medida que explicitam a necessidade de se adotar um conceito mais amplo, que permita estudar configurações com distintos desenhos. A escola californiana, por exemplo, enfatiza que, em seus estudos, procura analisar aglomerações que abrangem diversos portes de empresas, visando também incorporar à análise aglomerados de firmas não só pertencentes aos setores tradicionais. Essa escola coloca seu acento, em particular, na importância do quadro institucional das aglomerações e preocupa-se com a questão inovativa das aglomerações. Também os franceses consideram que os efeitos da proximidade espacial ganham contornos importantes nos processos inovativos. Portanto, esclarecem que a noção de sistemas produtivos locais se inspira nas análises da economia industrial e da economia regional sobre a inovação. Logo, para eles, a inovação adquire uma conotação mais territorializada.

Também para a abordagem dos sistemas nacionais de inovação e dos sistemas e arranjos produtivos locais, a inovação adquire um caráter localizado. Essa questão inovativa ganha ainda mais ênfase nessas proposições que se baseiam no pensamento neo-schumpeteriano evolucionista. Isto porque, ao destacarem a natureza sistêmica da inovação, compreendem a importância dos processos específicos e cumulativos de aprendizado, percebendo e ressaltando a relevância do local no processo de criação e difusão de inovação, já que ele compreende um espaço privilegiado de aprendizado interativo.

\section{Considerações finais}

A discussão a respeito da perda, ou não, da importância do local tem ganhado espaço na literatura, embora as conclusões não sejam, de forma alguma, consensuais. Há aqueles que entendem que, com a globalização, a dimensão local perde relevância, pois, segundo essa visão, os espaços nacionais ficam anulados na

(16) Veja a reflexão feita na Introdução do número especial da World Development (v. 27, n. 9, Sept. 1999). Nela, o próprio Schmitz ressalta que sua noção de eficiência coletiva não é adequada para capturar as ligações externas ao cluster como aquelas, por exemplo, com compradores externos, que são, segundo seu ponto de vista, cruciais para o desenvolvimento da aglomeração.

(17) Nessa direção, ver Humphrey e Schmitz (2000) que discutem o modo de inserção dos produtores locais em cadeias globais e formas de aprimorar a relação desses com grandes compradores. Schmitz (1999) aborda também tal questão ao analisar o caso da aglomeração calçadista do Vale do Rio dos Sinos no Rio Grande do Sul/Brasil. Ver também o trabalho de Gereffi (1999) que é referência na análise dos formatos das cadeias produtivas globais. 
atual fase do capitalismo, em decorrência de um processo de homogeneização do espaço econômico. Contudo, esse enfoque representa uma forma parcial de ver a globalização, à medida que sugere que tal fenômeno implica padronização do espaço econômico global e convergência de desenvolvimento.

Em contrapartida, outro conjunto de argumentos salienta a coexistência dos dois fenômenos - globalização e localização. As relações entre o espaço local e o global não são pacíficas, mas permeadas de conflitos, já que o global tenta impor sua hegemonia sobre o local. Nessa lógica, o processo de aceleração da globalização não anula nem as divergências, nem a importância dos contextos sociais e institucionais particulares. Pelo contrário, a dimensão local ganha total relevância, já que é vista como um fator determinante da capacidade inovativa. Isto porque são as relações entre os atores econômicos, sociais e políticos desses espaços locais que conformam sua capacidade inovativa e, portanto, definem a competitividade de um país, de uma região ou localidade. Nesse contexto, o Estado não perde seu papel, pelo contrário, sua intervenção coordenada nos diversos planos - nacional, regional e local - é chave para promover e garantir, diante da dinâmica global, o desenvolvimento de longo prazo dos espaços territoriais.

Uma série de pesquisas focando diversas experiências de aglomerações produtivas tem enfatizado a relação entre proximidade geográfica e vantagens competitivas. Em geral, esses estudos destacam a relevância das aglomerações industriais locais e regionais na busca pela competitividade e pelo dinamismo tecnológico de firmas de diferentes setores e vêem a promoção dessas aglomerações produtivas como uma alternativa viável e importante de desenvolvimento econômico. Esse reconhecimento tem também contribuído para que as políticas de cunho científico-tecnológica, industrial e/ou de desenvolvimento regional tenham como foco o conjuntos de atores, suas articulações e seus territórios. É importante o papel coordenador do Estado no sentido de apoiar e fomentar tais aglomerações mobilizando seus recursos locais, mas também recriando-os para enfrentar as oportunidades e desafios que se colocam. A ação do Estado em seus diferentes níveis é fundamental e a efetividade das políticas locais será reforçada pela sua articulação às estratégias nacionais na direção do desenvolvimento. Isto é, as políticas locais e regionais devem ser concebidas dentro de uma estratégia maior de desenvolvimento de longo prazo do país e não no sentido de gerar competição interterritorial a exemplo da "guerra fiscal".

Há uma convergência entre as diversas abordagens comentadas quanto ao entendimento de que as características socioeconômicas e institucionais locais são significativas para o desempenho econômico e inovativo dos espaços regionais. No entanto, há também aspectos distintos entre elas. Dentre esses, está o destaque dado à questão do aprendizado. Tal questão, no entanto, não está presente em todas as 
proposições discutidas. Não está, por exemplo, na abordagem da especialização flexível e dos distritos industriais. Em contrapartida, encontra-se bastante enfatizada naquelas proposições que levam em conta o referencial neoschumpeteriano evolucionista. Estas, ao perceberem que o aprendizado interativo é um aspecto-chave no novo contexto de desenvolvimento econômico e tecnológico, ressaltam a proximidade geográfica como característica de peso para promover o intercâmbio de conhecimentos tácitos.

Por fim, pode-se ainda comentar que, embora a revisão da literatura pareça indicar com nitidez a relevância que as aglomerações locais adquirem no atual contexto, uma vez que compreendem um espaço privilegiado de interação entre diferentes atores na busca de vantagens competitivas, há ainda uma série de aspectos a serem investigados. Nesse sentido, observa-se que a maioria desses estudos investiga as características das configurações locais dos países desenvolvidos e pouco examina as peculiaridades dessas configurações nos países em desenvolvimento. Dessa forma, abre-se espaço para aquelas pesquisas que buscam melhor compreender as tipologias dos sistemas locais desses países, bem como analisar até que ponto os ambientes locais facilitam a adaptação das empresas frente aos novos cenários que se desenham e, ainda, examinar os papéis que os setores público e privado podem desempenhar para o fomento e para a consolidação dessas aglomerações.

Por conseguinte, os sistemas e arranjos locais apresentam-se como uma importante e vantajosa unidade de análise, pois seu enfoque vai além das tradicionais visões baseadas na firma, enquanto uma organização individual e isolada, e em setores ou cadeias produtivas, já que centra seu olhar no grupo de agentes que fazem parte de um território/espaço específico e que estabelecem interações entre si e compreendem um lócus de aprendizagem particular. Assim, a abordagem dos arranjos e sistemas inovativos locais ressalta a importância do aprendizado interativo e, por conseguinte, privilegia uma análise que extrapola a preocupação com os fluxos de insumos e de produtos entre as empresas, já que o entendimento dos fluxos de informação e de conhecimento entre os diversos agentes se torna fundamental. Portanto, coloca em evidência e no centro de sua análise os processos de aprendizado, de construção de capacitações e de inovação. E, dessa forma, orienta o escopo das ações de política. Em outras palavras, ao levar em conta os elementos-chave do próprio conceito de sistemas e arranjos produtivos e inovativos locais, as políticas serão orientadas prioritariamente para a criaçãodifusão de conhecimento, para o estímulo a múltiplas formas de aprendizado e para a construção de competências que potencializem e ampliem a competitividade dos espaços locais. 


\section{Referências bibliográficas}

ALBAGLI, S. Globalização e espacialidade: o novo papel do local. In: CASSIOLATO, J. E.; LASTRES, H. M. M. (Ed.). Globalização e inovação localizada: experiências de sistemas locais no Mercosul. Brasília: IBICT/MCT, 1999. p. 181-198.

ALBUQUERQUE, E. Apresentação. Revista Brasileira de Inovação, v. 3, n. 1, jan./jun. 2004.

ANDRADE, M. C. de. Territorialidade, desterritorialidades, novas territorialidades: os limites do poder nacional e do poder local. In: SANTOS, M.; SOUZA, M. A. A. de; SILVEIRA, M. L. (Org.). Território: globalização e fragmentação. São Paulo: Hucitec, 2002. p. 213-220.

BATISTA Jr., P. N. Mitos da "globalização". Estudos Avançados, São Paulo, v. 12, n. 32, p. 125-186, jan./abr. 1998.

BECATTINI, G. The Marshallian industrial district as a socio-economic notion. In: PYKE, F.; BECATTINI, G.; SENGENBERGER, W. (Ed.). Industrial districts and inter-firm cooperation in Italy. Geneva: International Institute for Labor Studies, ILO, 1990. p. 3751.

BENKO, G. Economia, espaço e globalização: na aurora do século XXI. São Paulo: Hucitec, 1996.

. Organização econômica do território: algumas reflexões sobre a evolução no século XX. In: SANTOS, M.; SOUZA, M. A. A. de; SILVEIRA, M. L. (Org.). Território: globalização e fragmentação. São Paulo: Hucitec, 2002. p. 51-71.

BOYER, R. The convergence hypothesis revisited: globalization but still the century of nations? Cadernos CEPREMAP, Paris, n. 9403, Aug. 1993.

BRUSCO, S. The idea of the industrial district: its genesis. In: PYKE, F.; BECATTINI, G.; SENGENBERGER, W. (Ed.). Industrial districts and inter-firm cooperation in Italy. Geneva: International Institute for Labor Studies, ILO, 1990. p. 10-19.

Small firms and the provision of real services. In: PYKE, F.; SENGENBERGER, W. (Ed.). Industrial districts and local economic regeneration. Geneva: International Institute for Labor Studies, ILO, 1992. p. 177-196.

CASSIOLATO, J. E.; LASTRES, H. M. M. Inovação, globalização e as novas políticas de desenvolvimento industrial e tecnológico. In: CASSIOLATO, J. E.; LASTRES, H. M. M. (Eds.). Globalização e inovação localizada: experiências de sistemas locais no Mercosul. Brasília: IBICT/MCT, 1999. p. 767-799.

. O foco em arranjos produtivos e inovativos locais de micro e pequenas empresas. In: CASSIOLATO, J. E.; LASTRES, H. M. M.; MACIEL, M. L. (Org.). Pequena empresa: cooperação e desenvolvimento local. Rio de Janeiro: Relume Dumará: UFRJ, Instituto de Economia, 2003. p. 21-34.

Sistemas de inovação e desenvolvimento: as implicações de política. São Paulo em Perspectivas, v. 19, n. 1, p. 34-45, jan./mar. 2005.

CHESNAIS, F. A mundialização do capital. Rio de Janeiro: Xamã, 1996. 
CHESNAIS, F.; SAUVIAT, C. O financiamento da inovação no regime global de acumulação dominado pelo capital financeiro. In: LASTRES, H. M. M.; CASSIOLATO, J. E.; ARROIO, A. (Org.). Conhecimento, sistemas de inovação e desenvolvimento. Rio de Janeiro: Editora UFRJ; Contraponto, 2005. p. 161-219.

CORIAT, B. Automação programável: novas formas e conceitos de organização da produção. In: SCHMITZ, H.; CARVALHO, R. Q. (Org.). Automação, competitividade e trabalho: a experiência internacional. São Paulo: Hucitec, 1988. p. 13-62.

COURLET, C. Nova dinâmica de desenvolvimento e sistemas industriais localizados. Ensaios FEE, Porto Alegre, v. 14, n. 1, p. 9-25, 1993.

. Les systèmes productifs locaux: de la definition au modèle. In: DATAR (Délégation à l'aménagement du territoire et à l'action régionale). Réseaux d'entreprises et territories: regards sur lês systèmes productifs locaux. Paris: La Documentation Française, 2001. p. 17-61.

COUTINHO, L. A terceira revolução industrial e tecnológica: as grandes tendências de mudança. Economia e Sociedade, Campinas: Unicamp, n. 1, p. 69-87, ago. 1992.

DINIZ, C. C. O papel das inovações e das instituições no desenvolvimento local. In: ENCONTRO NACIONAL DE ECONOMIA, 29, 2001, Salvador. Anais... Salvador, 2001. p. 1-21. Disponível em: <http://www.anpec.org.br/encontro2001/artigos/200105383.pdf>. Acesso em: mar. 2010.

DOSI, G. Technical change and industrial transformation - the theory and an application to the semiconductor industry. London: Macmillan, 1984.

DOSI, G. et al. (Ed.). Technical change and economic theory. London: Pinter, 1988.

EDQUIST, C. (Ed.). Systems of innovation: technologies, institutions, and organizations. London: Pinter, 1997.

FREEMAN, C. The 'National System of Innovation' in historical perspective. Cambridge Journal of Economics, v. 19, n. 1, 1995, p. 5-24.

Innovation and growth. In: DODGSON, M.; ROTHWELL, R. (Ed.). The handbook of industrial innovation. Cheltenham: Edward Elgar, 1996. p. 78-93.

GARCIA, R. de C. Aglomerações setoriais ou distritos industriais: um estudo das indústrias têxtil e de calçados no Brasil. Dissertação (Mestrado em Economia)-Instituto de Economia, Universidade de Campinas, Campinas, 1996.

- Economias externas e vantagens competitivas dos produtores em sistemas locais de produção: as visões de Marshall, Krugman e Porter. Ensaios FEE, Porto Alegre, v. 27, n. 2, p. 301-324, out. 2006.

GEIGER, P. P. Des-territorialização e espacialização. In: SANTOS, M.; SOUZA, M. A. A. de; SILVEIRA, M. L. (Org.). Território: globalização e fragmentação. São Paulo: Hucitec, 2002. p. 233-46.

GEREFFI, G. International trade and industrial upgrading in the apparel commodity chain. Journal of International Economics, n. 48, p. 37-70, 1999.

HUMBERT, M. Globalização e globalização: problemas para países em desenvolvimento e implicações para políticas supranacionais, nacionais e subnacionais. In: LASTRES, H. M. 
M.; CASSIOLATO, J. E.; ARROIO, A. (Org.). Conhecimento, sistemas de inovação e desenvolvimento. Rio de Janeiro: Editora UFRJ; Contraponto, 2005. p. 259-289.

HUMPHREY, J.; SCHMITZ, H. The triple C approach to local industrial policy. World Development, v. 24, n. 12, p. 1859-1877, 1996.

. Governance and upgrading: linking industrial cluster and global value chain research. Institute of Development Studies, 2000. (Working Paper, 120).

JOHNSON, B. Introduction of Part I Systems of innovation: overview and basis concepts. In: EDQUIST, C. (Ed.). Systems of innovation: technologies, institutions, and organizations. London: Pinter, 1997.

; LUNDVALL, B-Å. Promoting innovation systems as a response to the globalising learning economy. Rio de Janeiro, 2000. (Nota técnica, 4).

KRUGMAN, P. Development, geography and economic theory. Cambridge, MA: MIT Press, 1995.

LASTRES, H. M. M.; CASSIOLATO, J. E. Systems of innovation, clusters and industrial districts: analytical and policy implications of convergence and differences in the approaches. In: GLOBELICS CONFERENCE SOUTH ÁFRICA, Pretoria, 3, nov. 2005.

; VARGAS, M. A.; LEMOS, C. Novas políticas na economia do conhecimento e do aprendizado. Rio de Janeiro, 2000. (Nota técnica, 3.1).

LEBORGNE, D.; LIPIETZ, A. L'après-fordisme: idées fausses et questions ouvertes. Problèmes Économiques, n. 2260, p. 13-24, jan. 1992.

LÓPEZ, A.; LUGONES, G. Los sistemas locales en el escenario de la globalización. In: CASSIOLATO, J. E.; LASTRES, H. M. M. (Ed.). Globalização e inovação localizada. Brasília: IBICT/MCT, 1999. p. 72-108.

LUNDVALL, B-Å. Innovation as an interactive process: from user-producer interaction to the national system of innovation. In: DOSI, G. et al. (Eds.). Technical change and economic theory. London: Pinter, 1988, p. 349-369.

et al. National systems of production, innovaton and competence building. Research Policy, n. 31, p. 213-231, 2002.

; BORRÁS, S. The globalising learning economy: implications for innovation policy. Report based on the TSER Programme DG XII, Commission of the European Union, Dec. 1997.

MARKUSEN, A. R. Região e regionalismo: um enfoque marxista. Espaço \& Debates, São Paulo, v. 1, n. 2, p. 61-99, maio 1981.

. Áreas de atração de investimentos em um espaço cambiante: uma tipologia de distritos industriais. Nova Economia, Belo horizonte, v. 5, n. 2, p. 9-44, dez. 1995.

et al. (Ed.). Second tier cities: rapid growth beyond the metropolis. London: University of Minnesota Press, 1999.

MARSHALL, A. Principles of Economics. London: MacMillan and Co., 1890.

MASKELL, P.; MALMBERG, A. Localised learning and industrial competitiveness. Cambridge Journal of Economics, 23, p. 167-185, 1999. 
NADVI, K.; SCHMITZ, H. Industrial clusters in less developed countries: review of experiences and research agenda. Discussion Paper, Brighton, v. 339, p. 1-101, Jan. 1994.

NADVI, K. M. Small firm industrial districts in Pakistan. Doctoral Thesis-University of Sussex, 1996.

NELSON, R.; WINTER, S. An evolutionary theory of economic change. Cambridge, Mass: Harvard University Press, 1982.

OMINAMI, C. (Ed.). La tercera revolution industrial. Buenos Aires: Grupo Editor Latinoamericano, 1986.

PACHECO, C. A. Fragmentos da nação. Campinas: Unicamp. IE, 1998.

PEREZ, C. Las nuevas tecnologias: una vision de conjunto. In: OMINAMI, C. (Ed.). La tercera revolucion industrial. Buenos Aires: Grupo Editor Latinoamericano, 1986.

PERROUX, F. Les poles de croissance. In: PERROUX, F. L'économie du XXe siècle. Paris: Presses Universitaires de France, 1961. p. 123-242.

PIORE, M. J.; SABEL, C. F. The second industrial divide: possibilities for prosperity. New York: Basic Books, 1984.

Les chemins de la prospérité: de la production de masse à la spécialisation souple. Paris: Hachette, 1989.

PORTER, M. Clusters and the new economics of competition. Harvard Business Review, p. 77-90, Nov./Dec. 1998.

POSSAS, M. L. Em direção a um paradigma microdinâmico: a abordagem neoschumpeteriana. In: AMADEO, E. J. (Org.). Ensaios sobre economia política moderna: teoria e história do pensamento econômico. São Paulo: Marco Zero, 1989. p. 157-177.

. Competitividade: fatores sistêmicos e política industrial. Implicações para o Brasil. In: CASTRO, A. B. de et al. (Org.). Estratégias empresariais na indústria brasileira: discutindo mudanças. Rio de Janeiro: Forense Universitária, 1996. p. 71-117.

RABELLOTTI, R. Is there an "Industrial District Model"? Footwear districts in Italy and Mexico compared. World Development, v. 23, n. 1, p. 29-41, 1995.

REDESIST. Glossário de arranjos e sistemas produtivos e inovativos locais. Jun. 2005. Disponível em: $<\underline{w w w . r e d e s i s t . i e . u f r j . b r}>$. Acesso em: 18 nov. 2005.

SCHMITZ, H. Pequenas empresas e especialização flexível em países menos desenvolvidos. São Paulo, FEA/USP, 1989. Paper apresentado no Seminário "Padrões Tecnológicos e Políticas de Gestão".

. Collective efficiency: growth path for small-scale industry. The Journal of Development Studies, v. 31, n. 4, p. 529-566, Apr. 1995.

. Global competition and local co-operation: success and failure in Sinos Valley, Brasil. World Development, v. 27, n. 9, p. 1627-1650, Sept. 1999.

SCHMITZ, H.; NADVI, K. Clustering and industrialization: introduction. World Development, v. 27, n. 9, p. 1503-1514, Sept. 1999. 
SCOTT, A. J. The geographic foundations of industrial performance. In: CHANDLER Jr., A. D.; HAGSTROM, P.; SOLVELL, O. (Ed.). The dynamic firm: the role of technology, strategy, organization and regions. Oxford: Oxford University Press, 1998. cap. 16.

STORPER, M. The resurgence of regional economies, 10 years later. In: STORPER, M. The regional world: territorial development in a global economy. New York, London: The Guilford Press, 1997a. p. 3-25.

Territories, flows, and hierarchies in the global economy. In: COX, K. R. (Ed.). Spaces of globalization: reasserting the power of the local. New York: The Guilford Press, 1997b. p. 19-43.

SUZIGAN, W. et al. Aglomerações industriais no Estado de São Paulo. In: ENCONTRO NACIONAL DE ECONOMIA, 28, 2000. Anais... Campinas, 2000.

TAVARES, M. da C., FIORI, J. L. (Org.). Poder e dinheiro: uma economia política da globalização. Petrópolis: Editora Vozes, 1997.

VAN DIJK, M. P.; RABELLOTTI, R. (Ed.). Enterprise clusters and networks in developing countries. London: Frank Cass, 1997. 209p.

VARGAS, M. A. Proximidade territorial, aprendizado e inovação: um estudo sobre a dimensão local dos processos de capacitação inovativa em arranjos e sistemas produtivos no Brasil. Tese (Doutorado em Economia)-Instituto de Economia, Universidade Federal do Rio de Janeiro, 2002. 